\title{
Analysis of The Factors Affecting China's Food Security and The Countermeasures
}

\author{
Liu Fang a , Liu Shuai * \\ College of economics and management, Jilin Agricultural University, Changchun, Jilin,China \\ a. liufang6940@sina.com,*Corresponding author: E-mail: liushuai82@gmail.
}

Keywords: Food security, The current situation of grain production in China, The main factors affecting food security.

\begin{abstract}
Food security is the foundation of a country's social stability and economic development. This paper compares the global food security with China's food situation, summarizes the main problems of China's food security, and explores the factors that affect China's food security, including the shortage of agricultural land resources, the inability to meet the needs of food production, the rapid growth of food demand, the aggravation of the imbalance of food supply and the threat from the international market. Based on this, the paper puts forward suggestions of relevant policy to ensure national food security, in order to provide a scientific basis for the policy formulation of relevant government departments.
\end{abstract}

\section{Introduction}

Food is an old and young topic ${ }^{[1]}$. Food is the basis of human survival and development. General secretary Xi Jinping emphasized in the nineteen major reports of the party, "to ensure national food security and to firmly put Chinese rice bowls in their hands". Food security is an important foundation for a country to achieve economic development, social stability and national security ${ }^{[2]}$. Since the founding of the people's Republic of China more than 70 years ago, in order to solve the problem of people's full and good food, China has adopted corresponding food security policies in different historical periods according to different national conditions, so that the people can have food in their hands without panic.

The issue of food security has always been a hot issue in academic circles. The existing research mainly analyzes and discusses it from the supply and demand, price, trade and other aspects of food, and puts forward quite a few suggestions on how to adjust the relationship between supply and demand of food, stabilize the market price of food, and promote circulation of food trade ${ }^{[3-6]}$. $<$ The white paper "China's food security" > said: "The people are the foundation of the country and the valley is the lifeblood of the people". Since food security is so important, what is the current state of global food security? In this context, what is the current situation of domestic food security? What are the specific factors that threaten food security? 


\section{Current situation of global food security}

The global food crisis and China's food security are different manifestations of the same problem ${ }^{[7]}$. If we want to study China's food security in an all-round way, we need to understand the background of global food security and analyze it in combination with this background. From the perspective of the international environment, global food shortage is a serious problem. In recent decades, although the phenomenon of global hunger and malnutrition has greatly reduced, it still continues to plague millions upon millions of people. According to the data released by the FAO, in 2018, the number of people in global food shortage reached 820 million, and more than 2 billion people could not stably obtain safe, nutritious and adequate food ${ }^{[8]}$. According to the latest report of world food security and nutrition, nearly 690 million people in the world will be hungry in 2020, accounting for $8.9 \%$ of the world's total population. Based on this, food security is still the focus of UN Framework documents and international scientific research. Throughout the overall situation of global food security, even if the effect of global food security governance gradually appears, the food production of poor and food deficient countries has been developed, which has created a better environment for China and the world's food security. Nevertheless, the challenges facing world food security are still severe, the proportion of hungry people in the world is still high, international food trade is facing the interference of protectionism and unilateralism ${ }^{[9]}$, and it is still a long way to go to achieve the goal of sustainable development of food.

At the present stage, the world is in a great change that has not happened in a hundred years. It is in a period of continuous transition and historical convergence. On the whole, global food consumption and production will continue to grow, and the overall situation of global food security will be improved by 2035, but the situation of food security in some regions is still severe, and the imbalance between regions is more prominent ${ }^{[10]}$. The spatial distribution the pattern of global food security presents the pattern of "high high agglomeration, low low agglomeration" [11]. Due to the complex international situation and the food security situation with deteriorating risks, it is necessary to effectively coordinate the joint development of international organizations, non-governmental organizations (NGOs), multinational corporations and other diversified subjects, and form a new situation of global food and agriculture governance, so as to more effectively deal with global issues such as food security ${ }^{[12-13]}$. In addition, in the future, the expectation of the international community for China will also increase. In the long run, China has only $2 / 3$ self - sufficiency rate and 1/3 import rate, which means that China needs to pay close attention to international food production and supply and international food trade to ensure the stable development of China's food security.

\section{Current situation of food security in China}

China is the largest country in the world in food production, consumption and import, and with the rapid development of industrialization and urbanization, food production and consumption have been in a tight balance for a long time, which will become the characteristics of China's food supply and demand situation for a long time ${ }^{[7]}$. China's food security does not affect the stable development of domestic economy and society, but also an important factor affecting international food supply and demand and price. In other words, China has always been the backbone of safeguarding world food security, and safeguarding China's food security is equivalent to safeguarding world food security. The white paper "China's food security" in 2019 clarifies China's food security concept of firmly maintaining world food security and establish a community of shared future for mankind. It is pointed out that China should adhere to the direction of agricultural development in the face of complex international environment, that is, to actively participate in global food and agriculture governance under the premise of ensuring national food security, so as to provide security for global food security. 
Since the reform and opening up, China's grain output has achieved stable growth for quite a few years ${ }^{[14]}$. < The white paper "China's food security" > points out that China's population accounts for next to $1 / 5$ of the world, and its food production accounts for about $1 / 4$ of the world. Since the reform and opening up, China has been relying on its own strength to ensure China's food security, realizing the historic change from "not enough to eat" to "enough to eat" and "eat well". This is not only a great achievement made by the Chinese people in their own development, but also a major contribution to world food security. At present, according to the data released by the National Bureau of statistics in 2020, China's total grain output will reach 669.49 million tons in 2020, 5.65 million tons more than that in 2019, an increase of $0.9 \%$, reaching the highest level in history. The continuous increase of grain output has effectively answered the question of "who will feed China", and laid a solid foundation for China's social and economic development.

Under these circumstances, both grain output and import had experienced a "double growth" phenomenon ${ }^{[15]}$. From 2003 to 2016, China's grain production peaked and fell back, realizing 12 consecutive increases in grain production. By 2018, China's total grain output was 658 million tons, which was 0.0371 million tons less than that in 2017, a decrease of $0.6 \%$. Grain production has dropped slightly, but the decrease is not large, and it is still at a high level, which is a good harvest year. Since 2018, China's grain production has begun to increase, showing the second is the state of growth (as shown in figure 1). Overall, the total grain output in 2020 will increase by $54.4 \%$ compared with that in 2003.

However, due to the increase of domestic grain demand, the obvious increase of the price of domestic grain, the inverted price at home and abroad and the obvious contradiction of grain structure during the epidemic period. China's corn import volume will reach a record 11.3 million tons in 2020, will increase of $135.7 \%$ over the previous year. The import volume of rice and rice was 2.23 million tons, a year-on-year increase of $2.7 \%$. In 2020, China will import 8.38 million tons of wheat, an increase of $140.2 \%$ over the previous year, equivalent to $87 \%$ of the annual quota. In addition, a large number of vegetable oils, pork, beef and mutton are heavily dependent on foreign markets, resulting in the annual increase of grain output and import in China.

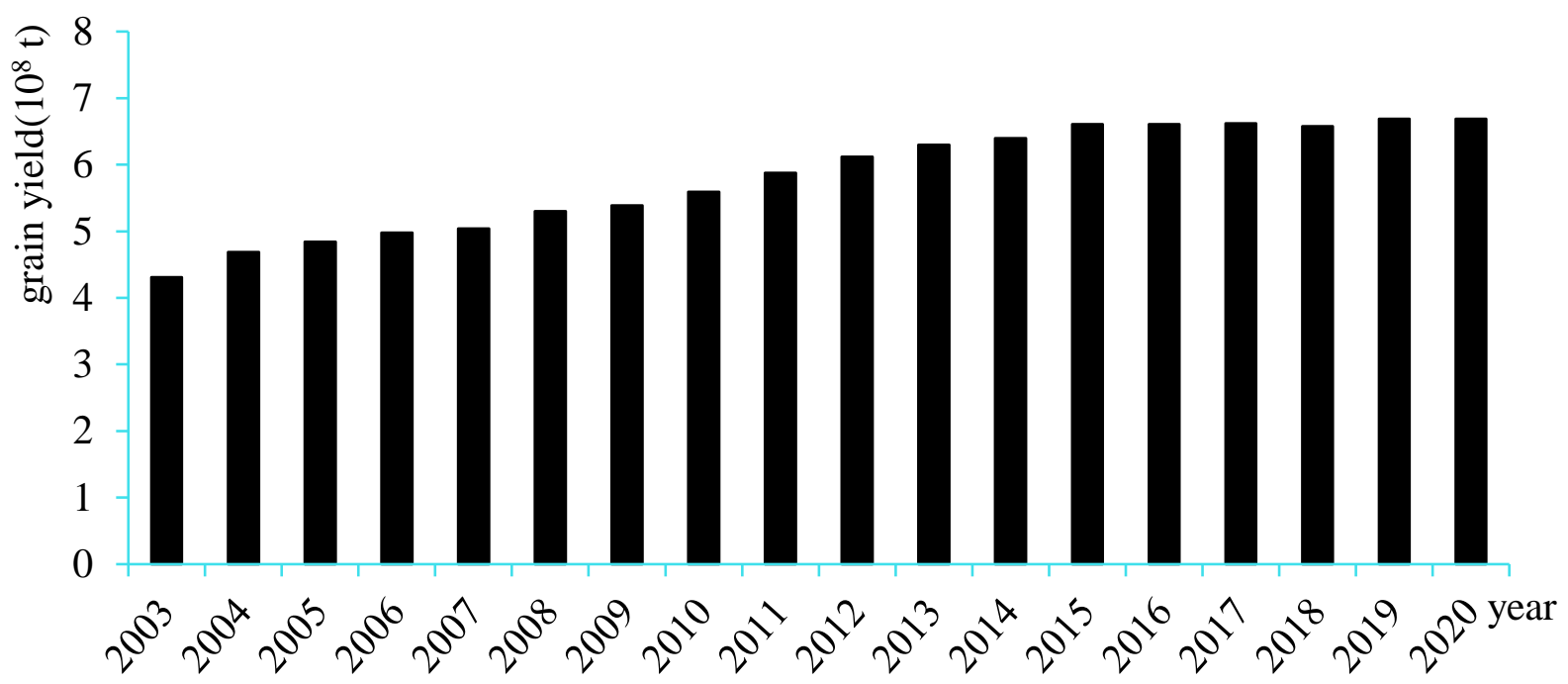

Figure.1 China's grain output in 2003-2020. 


\section{Factors threatening China's food security}

At the present stage, China's food security strategy is basically self - sufficiency of grain, absolute security of grain ration, and of course, the realization path and other issues. Obviously, there are still many shortcomings in the implementation of the strategy, which will be elaborated from three levels.

\subsection{The shortage of agricultural land resources can not meet the needs of food production}

As the most valuable non renewable resources in China, the quality of agricultural land has a serious impact on China's food security and the sustainability of cultivated land use. With the expansion of cities and towns and the construction of various types of parks, a large number of good farmland and good soil have been occupied, and a large number of permanent basic farmland have been built up. The rigidity of the land with the best conditions for farming has been reduced, and a large number of rural land has been abandoned. Li Shengfa and other studies show that the abandonment rate of cultivated land in mountainous areas in China is higher in the South and lower in the north at the provincial level. The abandonment rate of cultivated land in 2014-2015 was $14.32 \%{ }^{[16]}$, among which the abandonment rate of cultivated land in the Yangtze River Basin is the highest, and the abandonment rate of cultivated land in some areas even exceeded half. In addition, excessive reclamation, soil erosion and improper fertility of incorrect fertilization of agricultural land degradation from time to time ${ }^{[17]}$. Although the state now insists on the red line of 1.8 billion mu of cultivated land, and through the formulation and published a series of relevant policy documents, such as < the notice of the general office of the State Council on firm stopping the "non-agricultural" behavior of cultivated land $>$, it has stopped the abandonment of cultivated land, reduce the probability of reduction of agricultural land, and guarantee the quantity of agricultural land. But the industrial pollution, agricultural non-point source pollution, agricultural non-point source pollution problems such as the dominance of cultivated land and the supplement of inferior land. It will lead to the rapid decrease of soil organic matter and serious soil acidification ${ }^{[18]}$, which makes the quality of degradation of agricultural land gradually degraded. Therefore, the problem of ensuring the quality of agricultural land is also worthy of attention.

\subsection{The grain demand has entered a stage of rapid growth, aggravating the imbalance of grain supply}

Total grain consumption and structural changes are mainly affected by economic growth, total population and structural changes, residents' income growth and other factors ${ }^{[19]}$. With the rapid growth of population, Chinese residents' demand for food consumption has entered a stage of rapid growth.

First, China's population base will continue to increase. This is the new peak of China's population in 2020, with a total of 1.4 billion people, the largest population base in the world. And China's birth rate has always been higher than the death rate. Under the base of 1.4 billion people, the population growth rate continues to be greater than $3.3 \%$. The continuous increase of China's total population will bring about an increase in the demand for food.

Second, the outflow of rural labor is serious. At present, based on the gradual deepening of industrialization and urbanization, the number of rural population is declining, and the trend of farmers transferring to urban departments to seek non-agricultural employment is becoming more and more significant. A large number of young people give up agricultural production to work in cities, which directly leads to the aging of agricultural population, the hollowing out of agriculture and the bankruptcy of rural areas. According to the statistics of the National Bureau of statistics, China's rural population dropped from 808.37 million in 2000 to 55.162 million in 2019, a 31.76\% 
decline. According to the statistics of migrant workers monitoring survey report, the number of migrant workers in cities increased from 229.78 million in 2009 to 290.77 million in 2019, an increase of 60.99 million or $26.54 \%$. The outflow of the main rural labor force leads to the increase of labor productivity, which can not make up for the loss of labor force. The gap on the supply side of grain will continue to increase, aggravating the imbalance between supply and demand of grain.

Third, the development of urbanization promotes the upgrading of residents' food consumption structure, resulting in the growth of total food demand. According to the data of the National Bureau of statistics, China's urban population increased from 459.06 million in 2000 to 848.43 million in 2019, an increase of $84.82 \%$. With the rapid increase of urban population, the net food consumption population increases, which aggravates the demand for food and puts pressure on the sustainable and stable supply of food.

\subsection{International market threat}

Actually, the grain market has always been controlled by foreign countries. Four major grain groups occupying the major share of world grain trade have a history of 100 years. At present, 80\% of the world's grain trading volume is monotonically controlled by the four major grain enterprises ${ }^{[20]}$. In in the negotiation of China's accession to the WTO in 2001, China sacrificed part of its agricultural interests for the development of manufacturing industry and the entry of manufacturing products into the international market. Nowadays, China's "three rights" separation policy makes the majority of operators who have the right to operate can not get the direct subsidy of grain, and thus can not enjoy the agricultural interests they should have, which damages the interests of some operators and aggravates the phenomenon that part of the dominant power of China's grain market is occupied.

With the widespread spread of the new coronavirus, the resilience of the global food supply chain is insufficient. Novel coronavirus pneumonia has spread worldwide since 2020. As the largest country of grain import in China, Brazil, the second largest country in China's grain imports, is located in the forefront of high-risk countries. In order to curb the spread of COVID-19, many countries have adopted trade restrictive measures. Grain as a large volume, low value, and difficult to preserve products will be directly or indirectly disrupted by the spread of the epidemic. If the global epidemic continues to spread, China's grain imports will be impacted ${ }^{[21]}$. At the present stage, China's epidemic situation has been well controlled, while the trading countries need to export due to the grain hoarding, which will reduce food prices. It can be seen that China's food security will affect the international market to a certain extent, and will also be threatened by the international market.

\section{Countermeasures and suggestions to resolve the risk of China's food security}

\subsection{Consolidation of foundation and protection of farmland}

To ensure food security, we must ensure the absolute security of agricultural land resources. First of all, we should ensure the relative balance of the total amount of agricultural land and keep the red line of 1.8 billion mu. Secondly, on the basis of the total balance of farmland, we should ensure the relative balance of planting area of grain. Finally, we should pay attention to both quantity and quality to protect farmland. We should not only keep the quantity of farmland, but also the quality of farmland. It is suggested combining crop rotation with scientific cultivation, promote soil testing and formulated fertilization, mechanical deep ploughing and straw returning to protect the quality of farmland. At the same time, we should promote the government and the market, science and technology support the development of agricultural technology, cultivate new food varieties, and combine land use with land maintenance, so as to improve the level of land productivity and accelerate the pace of improving the quality of agricultural land. 


\subsection{Guarantee human resource elements and promote the modernization of food safety production}

Food security is not only a "three rural" issue, but also a national security issue. To ensure China's food security, it is necessary to ensure the main body of grain planting. First, governments at all levels should put forward appropriate policies to help and benefit local farmers according to local conditions. Second, it is necessary to give full play to the advantages of business entities and ensure their market competitiveness. For instance, the three provinces in the Northeast have areas of golden corn from nature, and generally operate family farms. The advantages of family farm are abundant capital strength, complete machinery and equipment for agricultural tillage and formed a systematic management of farm technology. Therefore, they should focus on giving full play to the main advantages of their family farms to improve food production. Third, relying on the strength of science and technology to cultivate professional and specialized farmers. By promoting the mechanization, intellectualization and intensive development of high technology, we can cultivate a large number of professional farmers and provide new impetus for food security.

\subsection{Strengthen publicity and education}

There is a serious waste of food on the table in China. Taking Chinese college students as an example, the amount of food waste per meal per student is 67.55 grams, and the waste rate is $14.54 \%$. Therefore, we must stop the waste on the table. The government should strengthen publicity of saving and protecting grain, and advocate the education of saving food with honor and shame. We can widely carry out food security education, food saving action and food security concept education in schools, government agencies, enterprises and institutions, so that every family has the awareness of food security, so as not to waste a grain of rice or a drop of water, and to maximize the role of food.

\subsection{Grasp China's new strategic layout}

We must unswervingly adhere to the basic principle of food security, have food in our hands and have a foothold in the fundamentals. Grasp the strategic layout of "four points and one line". We should maintain the stability of the overall market environment of international grain, use international resources to stabilize China's food import channels, ensure that international food imports to China can meet China's demand for rations and grains, and finally achieve the goal of winwin cooperation.

It is suggested that according to the actual situation of our country. We should establish and improve the support system for the sustainable and stable development of grain according to local conditions. To guarantee the input and risk of grain production, the extension of technology of grain production and the service of grain market. So that farmers can get average profit of society from investment in grain, and enhance the enthusiasm of farmers in the main grain producing areas. We should encourage farmers to invest in grain production, promote the transformation of advanced technology of grain planting and technology into productive forces, and promote the sustainable and stable development of grain in major grain producing areas.

\section{Acknowledgements}

The authors gratefully acknowledge the National Social Science Foundation of China "Research on food and ecological" double security "with the coordination of" resources, factors and policies "in the three great plains of China" Project 20 \& ZD094 and the National Social Science Foundation of China, efficiency review, target evaluation and Policy Optimization Research of corn storage policy reform Project (20BJY147). 


\section{References}

[1] HUANG Jikun. Recognition of Recent and Mid-long Term Food Security in China[J]. Issues in Agricultural Economy, 2021(01):19-26.

[2] JIANG Changyun, WANG Yijie. The Achievement,Experiences of Promoting Food Security in China Since the Founding of New China 70 Years Ago and Our Thinking about It[J]. Issues in Agricultural Economy,2019(10):1023.

[3] WANG Dewen, HUANG Jikun. An analysis of China farmers grain supply impact under the duel price system[J]. Economic Research Journal,2001(12):55-65+92.

[4] LU Wencong, HUANG Zuhui. Future Prospects of Grain Supply and Demand in China: A Regionalized Multimarket Model Simulation[J]. Economic Research Journal,2004(08):94-104.

[5] Lu Feng, Xie Ya. The Supply of and the Demand for Grains in China, and the Trend of Prices (1980 2007) [J]. Management World,2008(03):70-80+187.

[6] Zhong Funing, Xiang Jing. Impacts of Demographic Dynamics and Professional Structure on Food Demand[J]. Issues in Agricultural Economy,2012,33(09):12-16+110.

[7] Cao Baoming, Tang Lixia, Hu Bingchuan, Zhao Xia. Global Grain Crisis and China's Grain Security[J]. International Economic Review,2021(02):9-21+4.

[8] FAO. The State of Food Security and Nutrition in the World 2019:Safeguarding Against Economic Slowdowns and Downturns[M].United Nations:2019-07-15.

[9] TANG Lixia, ZHAO Wenjie, LI Xiaoyun. The Deep Logical Analysis of Global Food Security Evaluation System[J]. Journal of Huazhong Agricultural University(Social Sciences Edition),2020(05):151-159+175-176.

[10] Jin Sanlin, Liuyan, Liu Naixi. Impact of Long-Term Trends in Global Food Security on China and Strategy[J]. Development Research,2018(12):4-8.

[11] XIE Hualing, YANG Yanping. A Review of International Viewpoints on China's Food Security[J]. World Sci-Tech $R$ \& D,2020,42(06):633-645.

[12] Joachim Braun,Regina Birner. Designing Global Governance for Agricultural Development and Food and Nutrition Security [J]. Review of Development Economics,2017,21(2).

[13] Thomas Sikor,Graeme Auld,Anthony J Bebbington,Tor A Benjaminsen,Bradford S Gentry,Carol Hunsberger,AnneMarie Izac,Matias E Margulis,Tobias Plieninger,Heike Schroeder,Caroline Upton. Global land governance: from territory to flow?[J]. Current Opinion in Environmental Sustainability,2013,5(5).

[14] Zhang Wufeng. The string of food security cannot be relaxed at any time [J]. China Grain Economy,2020(07):12-13.

[15] Wu Juan. Studying on the Problems of Grain Security Protect in China[J]. Issues in Agricultural Economy, 2012,33(03):15-21+110.

[16] LI Shengfa, LI Xiubin, XIN Liangjie, TAN Minghong, WANG Xue, WANG Renjing, JIANG Min, WANG Yahui. Extent and distribution of cropland abandonment in Chinese mountainous areas[J]. Resources Science,2017,39(10):18011811.

[17] LUAN Yingying, ZHENG Dechun, ZHANG Guojun. Current Status of Black Soil Resources in Jilin Province and Countermeasures for Protection[J]. Journal of Northeast Agricultural Sciences,2018,43(05):41-42.

[18] Liu Shuai, Yu Xiao-yang, Wu Di. Investigation and Study on the Quality Protection of Farmers' Farmland in the Main Grain Producing Areas__Based on the Analysis of 446 Samples from Jilin Province[J]. Economic Review Journal,2019(02):79-87.

[19] ZHANG Wenli, SHEN Guiyin, CAO Hui, XU Xuegao, WANG Huimin. Major Agricultural Products Consumption Trend,Influence and Policy: During the 13th Five-year Period[J]. Issues in Agricultural Economy,2016,37(03):11$17+110$.

[20]JiazhongZheng,WeiguangWang,GuoshuaiLiu,YiminDing,XinchunCao,DanChen,B.A.Engel.Towardsquantificationo fthenationalwaterfootprintinriceproductionofChina:Afirstassessmentfromtheperspectivesofsingledoublerice[J].ElsevierB.V.,2020.

[21] LI Xiande, SUN Zhilu, JIA Wei, CAO Fangfang, CHEN Yangfen, YUAN Longjiang. Impacts of COVID-19 on Global Agricultural Market and Trade and Its Countermeasures[J]. Issues in Agricultural Economy,2020(08):4-11. 